\title{
Characteristics of users of online personalized genomic risk assessments: Implications for physician-patient interactions
}

\author{
Colleen M. McBride, PhD $D^{1}$, Sharon Hensley Alford, PhD ${ }^{2}$, Robert J. Reid, MD, $P h D^{3}$, \\ Eric B. Larson, MD, MPH $H^{3}$, Andreas D. Baxevanis, PhD ${ }^{4}$, and Lawrence C. Brody, PhD
}

\begin{abstract}
Purpose: To evaluate what psychological and behavioral factors predict who is likely to seek SNP-based genetic tests for multiple common health conditions where feedback can be used to motivate primary prevention. Methods: Adults aged 25-40 years who were enrolled in a large managed care organization were surveyed. Those eligible could $\log$ on to a secure study Web site to review information about the risks and benefits of a SNP-based genetic test and request free testing. Two primary outcomes are addressed: accessing the Web (yes or no) and deciding to be tested (completed a blood draw at the clinic) Results: Those considering genetic susceptibility testing did not hold genetically deterministic beliefs ( 0.42 on scale of 0 [behavior] to 1 [genetic]) but believed genetic information to be valuable and were confident they could understand such information. Individuals who believed it important to learn about genetics (odds ratio $=1.28$ ), were confident they could understand genetics (odds ratio $=1.26$ ), and reported the most health habits to change (odds ratio $=1.39$ ) were most likely to get tested. Conclusions: Individuals who present to health care providers with online genetics information may be among the most motivated to take steps toward healthier lifestyles. These motives might be leveraged by health care providers to promote positive health outcomes. Genet Med 2009:11(8):582-587.
\end{abstract}

Key Words: personalized genomics, risk assessment, internet, psychosocial predictors

E mboldened by the completion of the sequence of the human genome, many scientists envision a future in which personalized genomic risk information will be provided to individuals to motivate risk-reducing behaviors and improve primary intervention and treatment. ${ }^{1,2}$ One suggested approach is to conduct whole genome scans of healthy individuals and return personalized risk profiles that identify propensities to multiple health conditions. Ideally, this information would enable individuals to

From the ${ }^{1}$ Social and Behavioral Research Branch, National Human Genome Research Institute, National Institutes of Health, Bethesda, Maryland; ${ }^{2}$ The Department of Biostatistics and Research Epidemiology, Henry Ford Health System, Detroit, Michigan; ${ }^{3}$ Group Health Cooperative, Center for Health Studies, Seattle, Washington; and ${ }^{4}$ Genome Technology Branch, National Human Genome Research Institute, National Institutes of Health, Bethesda, Maryland.

Colleen M. McBride, PhD, Social and Behavioral Research Branch, National Human Genome Research Institute, Building 31, MSC 2073, 31 Center Drive, Room B1B54, Bethesda, MD 20892. E-mail: cmcbride@mail. nih.gov.

Disclosure: The authors declare no conflicts of interest.

Submitted for publication March 31, 2009.

Accepted for publication June 10, 2009

Published online ahead of print July 14, 2009

DOI: $10.1097 /$ GIM.0b013e3181b22c3a take precautions before they experience negative health outcomes.

Indeed, the first generation of single nucleotide polymorphism (SNP)-based testing is now being marketed directly to consumers. ${ }^{3}$ The resulting genomic profiles are based on simultaneously testing for multiple polymorphisms at multiple loci. At prices ranging from $\$ 399$ to $\$ 2500$ (with optional added service costs), these tests are still not affordable to most Americans. However, rapid advancements in analysis technologies and decreasing cost means that these tests will likely become affordable in the coming decade.

The lack of proven clinical utility of these tests raises concern among the scientific and medical communities who consider these tests to represent "premature translation." $4-6$ The speed at which genomic knowledge has been uncovered has left little time for health professionals to acquire the skills needed to accurately interpret such test results. ${ }^{7}$ However, the availability of these tests increases the likelihood that individuals will be presenting to primary care physicians with personalized genomic profiles in hand. Physicians may be appropriately skeptical of testing and have no clinical guidelines for fielding patient requests. Thus, insights gained regarding the factors that motivate individuals to be early adopters of such testing could be informative to physicians.

Currently, little is known about the psychological and behavioral factors that motivate individuals to seek genetic susceptibility testing for common preventable health conditions (e.g., heart disease, adult onset diabetes, or common cancers). What little is known comes predominantly from studies of rare hereditary cancer syndromes and Alzheimer disease. ${ }^{8,9}$ Individuals seeking genetic testing for these conditions have been relatively homogeneous with respect to socioeconomic status and race (well educated and white). Moreover, these individuals largely have been recruited from families identified to be at high risk for these syndromes where mutation carriers have up to $80 \%$ increased lifetime risk. Thus, not surprisingly, these individuals typically report perceiving themselves to be at high risk for these conditions and to feel concerned that they may be at genetic risk. ${ }^{8,10,11}$ These results may not generalize to the context of genetic testing for common health conditions in healthy individuals where gene variants act together with environmental and behavioral risk factors to increase risk, and genes alone confer relatively modest increases in risk, usually on the order of $20-30 \% .^{12}$

The rapid pace of genetic discovery has been complemented with increased distribution of health information through the Internet. Internet access to health information arguably can empower the public as health consumers because it enables user-controlled interactions with information and other customization capabilities, is available virtually free of charge, and covers a breadth of topics. ${ }^{13}$ Indeed, in the case of genomic testing, the Internet could provide a platform for a balanced 
presentation of information whereby individuals can consider, at their own pace and in privacy, whether or not to undergo such testing, all key to informed decision making. ${ }^{14}$ However, concerns too have been raised that overreliance on the Internet may create a "digital divide" due to unequal Internet access and distrust in the security of information shared online. ${ }^{15}$ Data available thus far on health information seekers who use the Internet show consistently that women, whites, and the highly educated are overrepresented. ${ }^{15}$

Concerns also have been raised that Internet health information seeking "triangulates" the patient-physician encounter in ways that can be challenging for both parties. ${ }^{16}$ Several editorials have raised practical questions about how physicians might handle patients who present them with genome scans, suggesting that these new technologies may distract from important and valid clinical assessments. ${ }^{17}$ However, little is known about the psychological and behavioral factors that characterize Internet information seekers generally or those seeking genetic information online. Consideration of these factors could help health systems and health care providers prepare for patient demand and, as such, inform early steps toward clinical integration of counseling and service delivery that might be prompted by such testing.

In 2006, the multiplex initiative, a preclinical, multicenter, prospective observational study, was launched. Our primary aim (and the focus of this report) is to evaluate with a population-based sample of healthy adults (i.e., a sampling frame with a known denominator) what factors predicted interest in and uptake of a multiplex genetic susceptibility test (MGST) for eight common health conditions. Our intent was to educate a representative sample of individuals about genetic testing while assessing their social, psychological, and behavioral characteristics. This enabled us to compare the characteristics of the sizable group who chose not to be tested with those who requested testing.

We obtained data describing our population-based sampling strategy in which hard-to-reach subgroups, specifically African Americans, men, and those with low education were oversampled (unpublished data). African Americans and men were least likely to complete the baseline survey and log onto the Web site, and African Americans were least likely to opt for genetic testing. In this report, we explore a broad array of factors previously identified as predictors of health information seeking, ${ }^{18}$ to address four questions of importance to understanding the implications of MGST being offered directly to consumers: (1) were multiplex information seekers inclined to hold genetically deterministic explanations for common preventable health conditions?; (2) were multiplex information seekers inclined to be "risk perceivers," that is, report high objective and subjective risk for the health conditions?; (3) were multiplex information seekers inclined to be "skilled information consumers," that is, report greater competence with the health care system and genetics?; or (4) were multiplex information seekers inclined to be "health information monitors," that is, especially interested in health information?

\section{MATERIALS AND METHODS}

\section{Study sample}

The sampling frame for the multiplex initiative was drawn from a pool of 350,000 commercially insured members of a large Midwestern health maintenance organization. Briefly, the sample included members identified in the health plans' enrollment files to be aged 25-40 years, enrolled continuously for at least 2 years, assigned to a primary care physician, and selfidentified as being either black or white. Diagnosis codes were used to exclude members who had been previously diagnosed with diabetes mellitus, atherosclerotic cardiovascular disease, osteoporosis, or cancer. A random sample of members who matched the selection criteria was drawn, oversampling for men, African Americans, and individuals living in areas where $>10 \%$ of residents had low levels education as determined by US census data. To oversample, we used the Master Patient Index that includes basic demographic descriptors of insured enrollees. The Master Patient Index included patients' selfreported race and gender. To approximate education status, we mapped the patient's address to the 2000 US Census. Neighborhood block groups were identified where $10 \%$ or more of the residents had high school or less than high school education; these blocks were considered low-education neighborhoods. We inferred that study participants residing in these areas were more likely to be of a lower education status themselves. Samples were then drawn for each of the three strata (race, gender, and neighborhood education) with the intent to have the final sample comprise about 50\% African Americans and 25\% each for the different combinations of strata (e.g., 25\% of African American males living in neighborhoods were characterized by low levels of education). An advance letter was sent to those sampled that included a \$2 bill, explained the survey, and provided a toll-free number to call to decline participation.

\section{Study procedures}

The flowchart of study procedures is depicted in Figure 1. Recruitment occurred from February 2007 to May 2008. Those who completed the baseline screening survey and deemed eligible sent a brochure describing the multiplex study, informa-

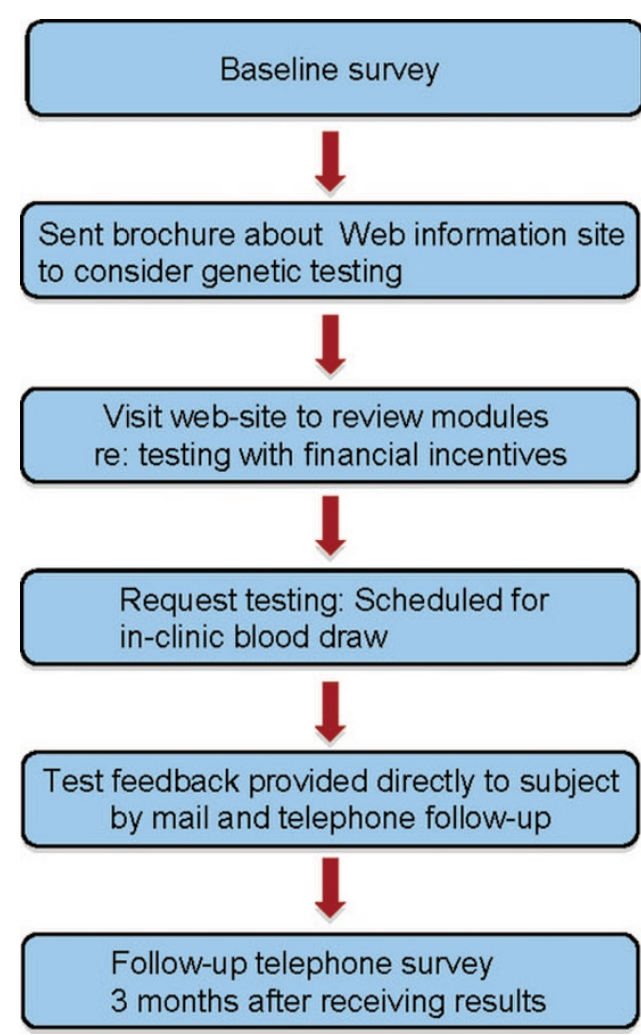

Fig. 1. Flow chart of study procedures. 
tion to access a secure study Web site (http://www. multiplex.gov), and a $\$ 20$ bill. Individuals who did not have access to the internet could request hard copies of information pages and could request testing by telephone. At the study Web site, participants could review five information modules about the MGST. The final module offered participants the free test, an offer they could accept or decline. Compensation (gift cards to a national retail chain) was provided for completing online surveys that followed each module. Those requesting testing were asked to schedule a clinic visit for a blood drawn. The Web site described that participants who were tested would receive: (1) a report explaining the meaning of their results in the mail about 6 months after blood collection; (2) a telephone call from a research educator to discuss the results; and (3) a follow-up telephone survey 3 months after receiving their test results. Genetic consultations were available at the participant's request. All procedures were approved by the Institutional Review Boards of the National Human Genome Research Institute and the Henry Ford Health System (HFHS).

\section{Multiplex test}

The selection process for the markers included in the MGST is described in detail elsewhere. ${ }^{19}$ Briefly, working groups including scientists from a broad range of disciplines engaged in deliberations to arrive at selection criteria and to apply these criteria to the evidence base for genetic variants associated with prevalent health conditions. Gene variants that met criteria identified by the working groups were subjected to an independent peer review by an expert panel whose recommendations were used to develop a final list of gene variants.

The outcome of this process was the development of the MGST that included 15 genetic polymorphisms associated with increased risk for eight common health conditions (type 2 diabetes; lung, colon, and skin cancers; coronary heart disease; hypercholesterolemia; hypertension; and osteoporosis). The eight selected health conditions are adult onset and "preventable," meaning that there are widely accepted evidence-based prevention recommendations for these conditions. ${ }^{20}$

\section{Measures}

The baseline questionnaire and the Web-based assessment of test decision (accessed on an average of about 6 weeks after completing the baseline survey) provide the prospective data for this report.

\section{Dependent variables}

Information seeking was indicated by two variables: accessing the Web site (yes or no) and getting tested as indicated by completing a blood draw at the clinic (yes or no).

\section{Independent variables}

Demographic characteristics included gender extracted from the HFHS enrollment database, self-identified race, and education as reported on the baseline telephone survey.

Beliefs about genetics as a cause of disease was based on a comparison of the individual's beliefs about the extent to which each of the eight health conditions were genetic, that is, "passed from one generation to the next" (1 [not at all] to 7 [completely]) versus the extent to which the health conditions were brought on by "health habits such as diet, exercise, and smoking" (1 [not at all] to 7 [completely]). A summary score across all health conditions was computed ranging from 0 to 1 , where 0 represented a general tendency to attribute health conditions to genetics alone and 1 represented attributing health conditions to behavior alone. The extent to which it was perceived to be important to learn more about genetics was assessed on a scale from 1 (not at all important) to 7 (very important).

Objective and subjective personal risk was characterized by seven variables: reported family history of six common health conditions (cancer, heart disease, osteoporosis, adult onset diabetes, high blood pressure, and high cholesterol; range, 0-6). Self-reported height and weight was used to calculate body mass index. Current smoking status was based on reporting ever having smoked and having smoked in the last 7 days. The number of health habits to change was assessed with an openended question in which the individual indicated specific health behaviors that they wanted to change (range, 0-6). Perceived health status was indicated by self-rating health as excellent, good, fair, or poor. Perceived risk (i.e., perceived lifetime likelihood of each of the eight health conditions; 1 [not at all likely] to 7 [completely likely]), perceived severity of the condition (1 [not at all serious] to 7 [very serious]), and related worry (1 [not at all worried] to 7 [very worried]) were assessed individually for each of the eight health conditions. An average score was calculated across the eight health conditions for perceived risk, severity, and worry.

Self-rated competency in using the health care system and genetics included: general health confidence, ${ }^{21}$ that is, level of agreement (1 [strongly disagree] to 7 [strongly agree]) with three statements (e.g., "you are confident in your ability to understand most health-related information," Cronbach's $\alpha=$ 0.71 ; and self-rated genetic competency ${ }^{21}$ based on a level of agreement (1 [strongly disagree] to 7 [strongly agree]) with six items (e.g., "you are confident in your ability to understand information about genetics," Cronbach's $\alpha=0.86$ ).

General health information seeking and perceived norms was measured with four variables. Individuals self-rated the frequency (4, daily; 3 , weekly; $2,<$ weekly; and 1 , never) in the past 30 days of "having sought information about ways to stay healthy or feel better." Access to the Internet was derived from combined responses to three questions: having ever gone online (yes or no), location of Internet usage (home, work, or both), and having a personal email account (yes or no). Access ranged from Level 1 (those who never went online) to Level 4 (those who use the Internet at home with a personal email account). Norms regarding perceived importance of seeking health information (e.g., "the people who mean the most to you think you should learn more ways you can keep yourself healthy") and norms regarding importance of staying healthy (e.g., "It's important for you to take care of your health because of the people who mean the most to you") were assessed. In each case, individuals rated their agreement (1 [strongly disagree] to 7 [strongly agree]) with four statements (two for each domain).

\section{Statistical analyses}

Means and proportions were computed to describe the distribution of independent variables. Bivariate associations of each of the independent variables with the two outcomes (logging on and getting tested) were tested for significance with $\chi^{2}$ and $t$ tests. Multivariate logistic regression models adjusting for race, education, and gender were tested that included all independent variables identified as significant in bivariate analyses at $P<0.05$ to predict each of the two outcome variables. Independent variables at $P>0.20$ were eliminated at each step using backward stepwise selection to arrive at a final model that "best" predicted each of the two outcome variables. 


\section{RESULTS}

\section{Recruitment}

We attempted baseline surveys with 6348 individuals; 1292 declined to complete the survey, 2614 were unreachable despite up to 10 repeated attempts, and 326 were deemed ineligible (e.g., reported having one of the health conditions). A total of 1959 individuals were eligible and completed the baseline survey; this yielded a $31 \%$ response rate and a $52 \%$ cooperation rate as defined by the American Association for Public Opinion Research (http://www.aapor.org). About one third of individuals who completed the survey were college graduates (37\%) and whites (37\%); $46 \%$ were male, and $63 \%$ were married. Participants reported having a family health history on an average for three $(\mathrm{SD}=1.5)$ of the MGST health conditions (Table 1$)$. The majority $(82 \%)$ considered themselves to be in good health. A total of 612 individuals who completed the baseline survey visited the study's Web site to consider testing; 528 registered a test decision. Of these, 266 provided written consent and had blood drawn for the MGST; 261 decided not to undergo testing.

\section{Were multiplex information seekers inclined to hold genetically deterministic explanations for common preventable health conditions?}

Figure 2 shows that at baseline, participants generally rated behavior as a greater causal factor than genetics for seven of the eight health conditions on the MGST. Participants tended to believe that common health conditions could be attributed relatively equally to genes and behavior $(X=0.42, \mathrm{SD}=0.11,0$ [behavior alone] to 1 [because of genes alone]; Table 1); these attributions did not predict logging on or getting tested. Considering it to be important to learn about genetics predicted participants' logging on and getting tested (logging on: odds ratio [OR], 1.21, 95\% CI [confidence interval]: 1.12-1.31; getting tested: OR 1.28, 95\% CI: 1.11-1.48; Table 2).

\section{Were multiplex information seekers inclined to be "risk perceivers," that is, report high objective and subjective risk for the health conditions?}

The 1959 who completed the baseline survey considered the health conditions on the test to be quite severe $(X=6.11$ on a 7-point scale) and believed that they had at least one related risk factor in need of change. However, participants perceived themselves to be at relatively modest risk for the health conditions ( $X=3.26$ on a 7-point scale) and were not particularly worried about getting the health conditions ( $X=3.98$ on a 7 -point scale). In multivariate analyses, none of the risk variables remained significant predictors of logging on. However, perceiving the health conditions to be severe reduced the likelihood of getting tested $(\mathrm{OR}=.73,95 \% \mathrm{CI}$ : 0.57-0.95, Table 2$)$. In contrast, perceiving one's self to have more health habits to change increased the likelihood of getting tested $(\mathrm{OR}=1.39$, 95\% CI: 1.13-1.72; Table 2).

\section{Were multiplex information seekers inclined to be "skilled information consumers," that is, report greater competence with the health care system and genetics?}

Participants reported high levels of confidence in their ability to navigate the health care system $(X=6.43$ on a 7-point scale) and to understand genetics ( $X=5.69$ on a 7-point scale). Neither area of confidence was a predictor of logging on in multivariate analyses, but confidence to understand genetics was a significant predictor of getting tested $(\mathrm{OR}=1.26,95 \%$
CI: 1.05-1.51; Table 2), whereas health system confidence was not. For each unit of increase in confidence to understand genetics, the likelihood of getting tested increased accordingly.

\section{Were multiplex information seekers inclined to be "health information monitors," that is, especially interested in health information?}

Fully two thirds of the participants had high levels of access to the Internet. Having more Internet access was a significant predictor of logging on in multivariate analyses $(\mathrm{OR}=1.26$, 95\% CI: 1.11-1.44) but was not associated with getting tested. General health information seeking also was not associated with either logging on or getting tested.

\section{DISCUSSION}

Only one third of those offered state-of-the-science free genetic testing logged on to a study Web site to review information about the pros and cons of being tested. Of those who viewed the information pages on the Web site, half considered the pros and cons of free testing and decided not to be tested. Our results suggest that when provided with balanced information, consumers recognize the limitations and utility of receiving personal genetic profiles; half decided against testing. However, up to half may regard such information to be useful even with its limitations.

We found no evidence that those who considered or sought testing were inclined to overestimate the contributions of genetics to common health conditions or to underestimate behavioral risk factors. On the contrary, those opting for testing held the same balanced view of the genetic contribution to disease as those who chose not to be tested. However, those who felt it to be most important to learn about genetics and felt confident in their ability to understand test results clearly were overrepresented among the genetic information seekers.

Frequent internet users and those who considered it to be most important to learn about genetics were most inclined to seek testing. Being active seekers of general health information was not an important predictor. Thus, genetics may hold special allure and generate new groups of health information seekers. It is important to note that disparities in access and use of online health information mean that some subgroups remain underserved. ${ }^{15}$ Thus, those presenting to primary care providers will likely be the most Internet savvy and may well have sought a variety of other online health information.

Perceiving one's self to have health habits in need of change was a positive predictor of getting tested. Fully, one third of those participating in the study were obese or current cigarette smokers, suggesting that reporting health habits to change might be a surrogate indicator of desire to decrease risk. Individuals may see genetic susceptibility testing as a step in the direction of getting healthy. Indeed, previous studies of genetic testing for susceptibility to lung cancer that have targeted cigarette smokers have reported that those who sought testing were the most motivated to quit smoking. ${ }^{23,24}$

Individuals presenting to their health care providers with personalized genome scans appreciate that both genes and environment influence common disease risk and believe that genetic information has value. Health care providers might leverage tested individual's motives to be healthier to direct these individuals to other evidence-based risk assessments. Indeed, others 25 have shown that when genetic testing is combined with family history information, patients may be more influenced by family history information than genetic results. Thus, by being 
Table 1 Bivariate associations between psychosocial factors and information seeking outcomes

\begin{tabular}{|c|c|c|c|c|c|}
\hline & \multirow{3}{*}{$\begin{array}{l}\text { Completed baseline survey } \\
\qquad(N=1959)\end{array}$} & \multicolumn{4}{|c|}{ Information seeking outcomes } \\
\hline & & \multicolumn{2}{|c|}{ Logged on } & \multicolumn{2}{|c|}{ Got tested } \\
\hline & & No $(n=1347)$ & Yes $(n=612)$ & No $(n=261)$ & Yes $(n=266)$ \\
\hline \multicolumn{6}{|l|}{ Beliefs about genetics } \\
\hline $\begin{array}{l}\text { Mean perceived effects of genes and } \\
\text { behavior on health conditions; } 0 \text {, } \\
\text { entirely behavior-1, entirely } \\
\text { genetics (SD) }\end{array}$ & $0.42(0.11)$ & $0.42(0.11)$ & $0.42(0.11)$ & $0.41(0.11)$ & $0.42(0.10)$ \\
\hline $\begin{array}{l}\text { Importance of learning about genes, scale } \\
1-7 \text { (SD) }\end{array}$ & $5.55(1.47)$ & $5.48(1.51)$ & $5.68(1.36)^{a}$ & $5.59(1.43)$ & $5.83(1.31)^{b}$ \\
\hline \multicolumn{6}{|l|}{ Personal risk and related concern } \\
\hline $\begin{array}{l}\text { Mean conditions with family history, } \\
\text { possible range: } 0-6(\mathrm{SD})\end{array}$ & $3.12(1.5)$ & $3.07(1.51)$ & $3.22(1.49)$ & $3.10(1.55)$ & $3.36(1.48)^{b}$ \\
\hline $\mathrm{BMI}>30(\%)$ & 35 & 36 & 33 & 36 & 30 \\
\hline Current smoker $(\%)$ & 28 & 29 & 28 & 28 & 30 \\
\hline Perceive health to be excellent (\%) & 23 & 22 & 24 & 23 & 26 \\
\hline $\begin{array}{l}\text { Mean perceived risk for health conditions, } \\
\text { scale } 1-7 \text { (SD) }\end{array}$ & $3.26(1.09)$ & $3.27(1.18)$ & $3.23(1.17)$ & $3.21(1.23)$ & $3.32(1.10)$ \\
\hline $\begin{array}{l}\text { Mean number of health habits to change, } \\
\text { range, } 0-4 \text { (SD) }\end{array}$ & $1.35(0.88)$ & $1.34(0.85)$ & $1.41(0.85)$ & $1.28(0.88)$ & $1.52(0.89)^{a}$ \\
\hline $\begin{array}{l}\text { Mean perceived severity of health } \\
\text { conditions, scale } 1-7 \text { (SD) }\end{array}$ & $6.11(0.79)$ & $6.15(0.79)$ & $6.02(0.80)^{c}$ & $6.13(0.80)$ & $5.90(0.78)^{a}$ \\
\hline $\begin{array}{l}\text { Mean worry about health conditions, } \\
\text { scale 1-7 (SD) }\end{array}$ & $3.98(1.53)$ & $4.03(1.56)$ & $3.86(1.49)^{b}$ & $3.94(1.58)$ & $3.86(1.38)$ \\
\hline \multicolumn{6}{|l|}{$\begin{array}{l}\text { Perceived competency in dealing with health } \\
\text { system and genetics }\end{array}$} \\
\hline $\begin{array}{l}\text { Confident to navigate health care system, } \\
\text { scale 1-7 (SD) }\end{array}$ & $6.43(0.73)$ & $6.40(0.76)$ & $6.50(0.65)^{a}$ & $6.48(0.70)$ & $6.51(0.62)$ \\
\hline $\begin{array}{l}\text { Confident can understand genetics, scale } \\
\text { 1-7 (SD) }\end{array}$ & $5.69(1.06)$ & $5.67(1.06)$ & $5.75(1.05)$ & $5.66(1.13)$ & $5.84(0.95)^{b}$ \\
\hline \multicolumn{6}{|l|}{$\begin{array}{l}\text { General health information seeking and } \\
\text { perceived norms }\end{array}$} \\
\hline $\begin{array}{l}\text { Frequency of health information seeking, } \\
\text { scale } 1-4(\mathrm{SD})\end{array}$ & $2.30(0.84)$ & $2.30(0.84)$ & $2.30(0.85)$ & $2.36(0.87)$ & $2.28(0.84)$ \\
\hline $\begin{array}{l}\text { Perceived norm: important to pursue } \\
\text { ways to stay healthy, scale } 1-7 \text { (SD) }\end{array}$ & $4.61(1.86)$ & $4.69(1.85)$ & $4.44(1.88)^{a}$ & $4.51(1.90)$ & $4.30(1.90)$ \\
\hline $\begin{array}{l}\text { Perceived norm: important to stay healthy } \\
\text { for others, scale 1-7 (SD) }\end{array}$ & $6.00(1.21)$ & $6.04(1.10)$ & $5.92(1.16)^{b}$ & $5.94(1.15)$ & $5.94(1.09)$ \\
\hline Access to internet $(\%)$ & 68 & 67 & $71^{c}$ & 71 & 70 \\
\hline $\begin{array}{l}\text { Ever invited to participate in clinical } \\
\text { research (\%) }\end{array}$ & 14 & 13 & $16^{b}$ & 13 & $20^{b}$ \\
\hline $\begin{array}{l}{ }^{a} P<0.01 \\
{ }^{b} P<0.05 \\
{ }^{c} P<0.001\end{array}$ & & & & & \\
\hline
\end{tabular}

"net friendly" (i.e., avoiding a dismissive attitude toward genetic information), physicians might be able to partner with patients for health promotion. ${ }^{16}$

To our knowledge, this is the first population-based (i.e., with a known denominator) study to prospectively evaluate the effects of offering MGST to a large and demographically heter- ogeneous population of healthy adults. Despite this considerable strength, there are some limitations. Given the large sample size, many of the relatively small associations between psychosocial factors and primary outcomes were statistically significant but may not be clinically meaningful. To reduce the burden of research participation and increase the external validity of 


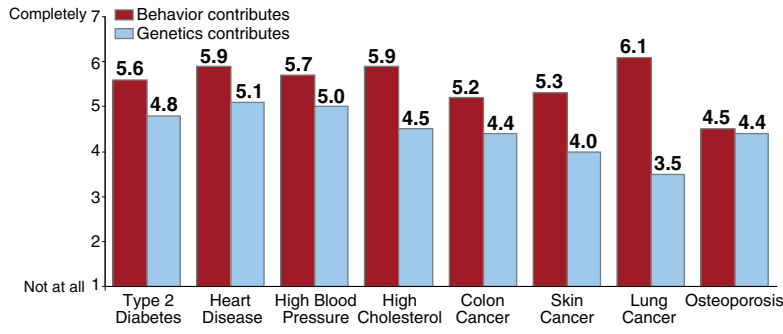

Fig. 2. Participant ratings of factors contributing to eight health conditions on the multiplex genetic susceptibility test.

Table 2 Final multivariate logistic regression model for psychological and behavioral predictors of getting tested after adjusting for race and education

\begin{tabular}{lcc}
\hline Predictors & Odds ratio & $\begin{array}{c}95 \% \text { confidence } \\
\text { interval }\end{array}$ \\
\hline Perceived severity of health conditions & 0.73 & $0.57-0.95$ \\
Confidence can understand genetics & 1.26 & $1.05-1.51$ \\
Importance of learning about genetics & 1.28 & $1.11-1.48$ \\
Number of health habits to change & 1.39 & $1.13-1.72$ \\
Ever invited to participate in research & 1.40 & $0.86-2.30$ \\
\hline
\end{tabular}

our findings, many of our psychosocial measures were extracted from larger validated scales in ways that may have diminished the rigor of the measures. Offering MGST at no charge to those with health insurance is not likely to represent how such testing ultimately will be disseminated. Thus, these findings in many ways represent a "best case" scenario. Evaluating different coverage scenarios, such as with and without copays, has been shown previously to influence how patients use services ${ }^{26}$ and also could greatly influence which patients avail themselves of genetic testing.

In closing, direct-to-consumer availability of genomic testing profiles gives health consumers new, health information that as yet has no established clinical utility. Understanding early adopters' motives for seeking testing can be informative to physicians in managing patients who present with genomic profiles.

\section{REFERENCES}

1. Go VL, Wong DA, Wang Y, Butrum RR, Norman HA, Wilkerson L. Diet and cancer prevention: evidence-based medicine to genomic medicine. J Nutr 2004;134(suppl 12):3513S-3516S.

2. Bell J. Predicting disease using genomics. Nature 2004;429:453-456.

3. Katsanis SH, Javitt G, Hudson K. Public health. A case study of personalized medicine. Science 2008;320:53-54

4. Hunter DJ, Khoury MJ, Drazen JM. Letting the genome out of the bottlewill we get our wish? N Engl J Med 2008;358:105-107.
5. Haga SB, Khoury MJ, Burke W. Genomic profiling to promote a healthy lifestyle: not ready for prime time. Nat Genet 2003;34:347-350.

6. Lunshof JE, Pirmohamed M, Gurwitz D. Personalized medicine: decades away? Pharmacogenomics 2006;7:237-241.

7. Feero WG, Guttmacher AE, Collins FS. The genome gets personal-almost. JAMA 2008;299:1351-1352.

8. Roberts JS, Cupples LA, Relkin NR, Whitehouse PJ, Green RC. Genetic risk assessment for adult children of people with Alzheimer's disease: the Risk Evaluation and Education for Alzheimer's Disease (REVEAL) study. $J$ Geriatr Psychiatry Neurol 2005;18:250-255.

9. Armstrong K, Micco E, Carney A, Stopfer J, Putt M. Racial differences in the use of BRCA1/2 testing among women with a family history of breast or ovarian cancer. JAMA 2005;293:1729-1736.

10. Henrikson NB, Harris JN, Bowen DJ. Predictors of self-referral into a cancer genetics registry. Cancer Epidemiol Biomarkers Prev 2007;16:1387-1392.

11. Lipkus IM, Iden D, Terrenoire J, Feaganes JR. Relationships among breast cancer concern, risk perceptions, and interest in genetic testing for breast cancer susceptibility among African-American women with and without a family history of breast cancer. Cancer Epidemiol Biomarkers Prev 1999;8: 533-539.

12. Lohmueller KE, Pearce CL, Pike M, Lander ES, Hirschhorn JN. Metaanalysis of genetic association studies supports a contribution of common variants to susceptibility to common disease. Nat Genet 2003;33:177-182.

13. Bernhardt JM, McClain J, Parrott RL. Online health communication about human genetics: perceptions and preferences of internet users. Cyberpsychol Behav 2004;7:728-733.

14. Green MJ, McInerney AM, Biesecker BB, Fost N. Education about genetic testing for breast cancer susceptibility: patient preferences for a computer program or genetic counselor. Am J Med Genet 2001;103:24-31.

15. Lorence D, Park H. Group disparities and health information: a study of online access for the underserved. Health Informatics $J$ 2008;14:29-38.

16. Wald HS, Dube CE, Anthony DC. Untangling the web - the impact of Internet use on health care and the physician-patient relationship. Patient Educ Couns 2007;68:218-224.

17. McGuire AL, Burke W. An unwelcome side effect of direct-to-consumer personal genome testing: raiding the medical commons. JAMA 2008;300: $2669-2671$

18. Griffin RJ, Dunwoody S, Neuwirth K. Proposed model of the relationship of risk information seeking and processing to the development of preventive behaviors. Environ Res 1999;80:S230-S245.

19. Wade CH, McBride CM, Kardia S, Brody LC. An evidence-based process to identify genetic variants for use in research on genetic testing for common health conditions. Public Health Genomics In Press.

20. Emmons K, Smedley B, Syme S. Behavioral and social science contributions to the health of adults in the United States. In: Smedley BD, Syme S, editors. Institute of Medicine. Promoting health: intervention strategies from social and behavioral research. Washington DC: National Academy Press, 2009: 254-321.

21. Chew LD, Griffin JM, Partin MR, et al. Validation of screening questions for limited health literacy in a large VA outpatient population. J Gen Intern Med 2008;23:561-566.

22. Parrott RL, Silk KJ, Condit C. Diversity in lay perceptions of the sources of human traits: genes, environments, and personal behaviors. Soc Sci Med 2003;56:1099-1109.

23. McBride CM, Bepler G, Lipkus IM, et al. Incorporating genetic susceptibility feedback into a smoking cessation program for African-American smokers with low income. Cancer Epidemiol Biomarkers Prev 2002;11:521-528.

24. O'Neill SC, White DB, Sanderson SC, et al. The feasibility of online genetic testing for lung cancer susceptibility: uptake of a web-based protocol and decision outcomes. Genet Med 2008;10:121-130.

25. Tarini BA, Singer D, Clark SJ, Davis MM. Parents' concern about their own and their children's genetic disease risk: potential effects of family history vs genetic test results. Arch Pediatr Adolesc Med 2008;162:1079-1083.

26. Curry SJ, Grothaus LC, McAfee T, Pabiniak C. Use and cost effectiveness of smoking-cessation services under four insurance plans in a health maintenance organization. N Engl J Med 1998;339:673-679. 